\title{
Entrapment of the Median Nerves and Brachial Arteries in the Lower Arms Bilaterally and Additional Origin of Biceps brachii Muscle. Case Report
}

\author{
Compresión Bilateral del Nervio Mediano y de la Arteria Braquial en la Parte Distal \\ del Brazo y Origen Adicional del Músculo Bíceps Braquial. Reporte de Caso
}

Niladri Kumar Mahato

MAHATO, N. K. Entrapment of the median nerves and brachial arteries in the lower arm bilaterally and additional origin of biceps brachii muscle. Case report. Int. J. Morphol., 28(4):1241-1244, 2010.

SUMMARY: Neuro-vascular entrapments associated with variations observed in the origins of muscles in the arm are not uncommon. Though additional heads of biceps brachii muscle and extra fibres of brachialis muscles have been demonstrated earlier, bilateral additional heads of the biceps are rarely seen, especially with entrapment of the median nerve and the brachial arteries in both the arms. The present study reports conspicuous heads of the biceps brachii originating extensively from the medial inter-muscular septum, sharing its origin with the brachialis muscle. The extra origins of the muscle formed long musculo-aponeurotic tunnels. The tunnels measured eight centimeters in length extending from the lower arm to the cubital-fossa. Both the median nerve and the brachial arteries passed through the tunnel. The lower aspect of the left tunnel exhibited origins of fibres belonging to the superficial flexors of the forearm. The neuro-vascular structures did not give any branches in the tunnel. Awareness of such variations can aid clinicians in diagnosing and treating such neuropathies and vascular compromise.

KEY WORDS: Median nerve; Brachial artery; Biceps brachii muscle; Entrapment neuropathy; Inter-muscular septum.

\section{INTRODUCTION}

The median nerve and the brachial artery form the main neurovascular bundle that crosses the mid and lower arm (Williams et. al., 1989; McNamara, 2003). These structures are situated very near to the medial aspect of the biceps brachii and the brachialis muscles and descend very close in front of the medial intermuscular septum. The biceps brachii muscle originates by two heads from sites on the scapula and usually has no attachment on the humerus. Additional heads of attachments (origins) of the biceps on the humerus have been reported earlier RodriguezNiedenführ et al., (2003). The brachialis muscle, on the other hand, originates extensively from the antero-medial and the antero-lateral surfaces of the shaft of the humerus. Several variations in the attachments of the brachialis muscle have been documented in literature occasionally associated with anomalous origins involving other arm muscles including accessory muscles (Loukas et. al., 2006).
It is important to note that the presence of the median nerve - brachial artery complex in close vicinity of the medial inter-muscular septum and the medial aspects of the biceps and brachialis muscles make them susceptible to varying degrees of entrapment in situations of unusual origins of these muscles. The anatomy of median nerve entrapments have been extensively studied in context of anomalous origins of these two muscles in the distal arm (Gessini et al., 1983; Bilecenoglu et al., 2005). Brachial artery compromises, under similar circumstances, have been reported by observers like Bassett et al. (1994). Entrapment neuropathies are quite common in the median nerve due to compression at sites below the elbow (Birch et al., 1998; Bilecenoglu et al.). It should however be noted that fibrous, fibro-muscular or purely muscular encroachments may give rise to median nerve - brachial artery compressions in the mid and distal arm. 


\section{CASE REPORT}

The case presented in this study was detected during routine undergraduate dissection session in the Department of Anatomy of the institution. The cadaver belonged to a 70 year old male individual. Neurovascular tunnels were observed in both its upper limbs in the distal parts of the arms. The observations made in the right arm showed (Fig.1):

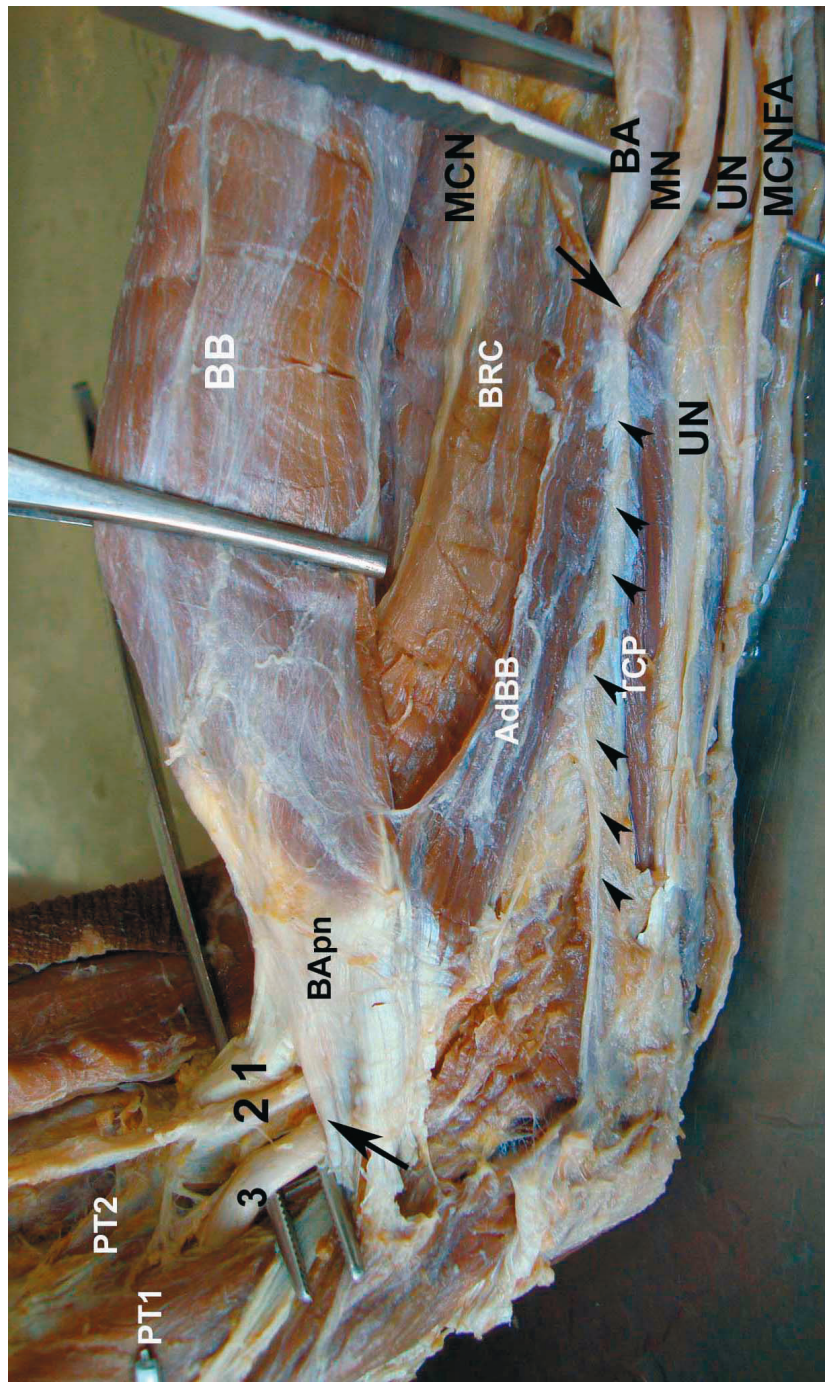

Fig. 1. Dissection at the right lower arm and the front of elbow showing entrapment of the neuro-vascular bundle. The extent of the tunnel is shown by arrows. Arrowheads mark the medial intermuscular septum. BA=Brachial artery, $\mathrm{MN}=$ Median nerve, $\mathrm{UN}=$ Ulnar nerve, MCNFA= Medial cutaneous nerve of the forearm, $\mathrm{MCN}=$ Musculocutaneous nerve. $\mathrm{BB}=$ Biceps brachii, $\mathrm{BRC}=$ Brachialis, BApn=Bicipital aponeurosis, $\mathrm{AdBB}=$ Additional head of Biceps brachii, $\mathrm{TCP}=$ Triceps brachii. PT1 \& PT2= Two heads of Pronator Teres.1= Biceps tendon, $2=$ Brachial artery and 3= Median nerve at the cubital fossa.
(1) a musculo-fascial tunnel of eleven centimeters length, extending from the medial part of the mid-arm up to the ante-cubital fossa, (2) the floor the tunnel was formed by the medial inter-muscular septum and roofed by an additional origin of the biceps brachii muscle, (3) the additional head was observed not only to originate from the anterior aspect of the medial inter-muscular septum but some of its lateral fibers were also seen to be attached to the adjacent brachialis muscle. This additional head of the biceps brachii muscle joined the medial margin of the bicipital expansion. The

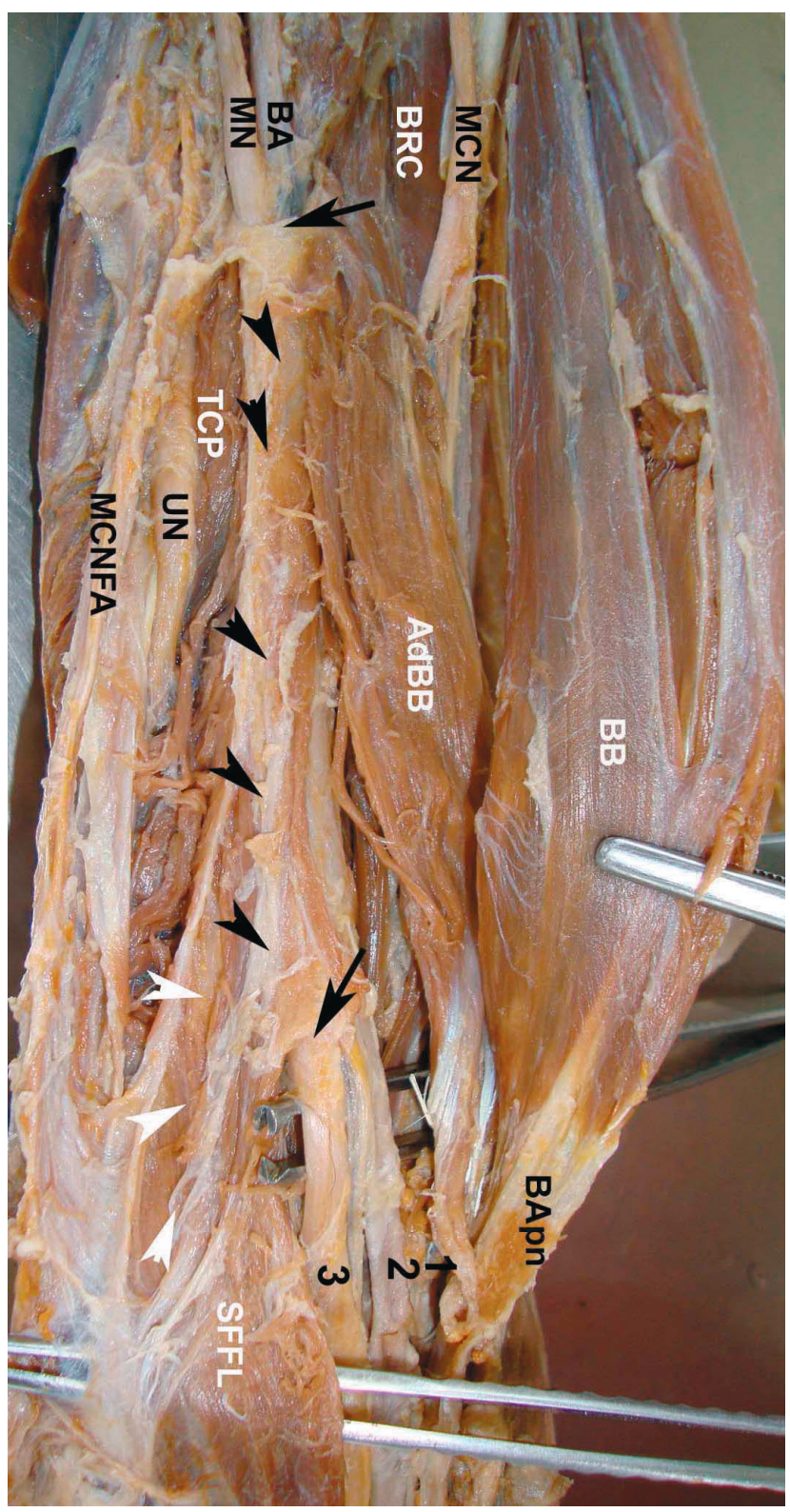

Fig. 2. Dissection of the left lower arm similar to Fig.1. White arrows demonstrate upward extension of origin of the superficial forearm flexors (SFFL) towards the medial inter-muscular septum. Other abbreviations are as in Fig.1. 
medial inter-muscular septum presented (4) conspicuous fibres belonging to the medial head of the triceps muscle that (5) originated from the medial inter-muscular septum and arched over the ulnar nerve to meet the medial margin of the normal medial head of the triceps muscle. The unusually long musculo-fascial tunnel contained the median nerve as well as the brachial artery; the former placed medial to the later. Beyond the tunnel the median nerve passed between the two heads of the pronator teres muscle. The brachial artery branched normally at the elbow.

Observations in the left arm revealed (Fig.2): (1) a fascial tunnel measuring eight centimeters, beginning at the lower arm and extending up to the ante-cubital fossa. The tunnel was limited posteriorly by the medial inter-muscular septum. (2) This tunnel was surrounded by a consistent thick fascia that provided an additional origin to the biceps brachii muscle. (3) The additional head was observed to bear fibres from the brachialis muscle on the lateral side of the tunnel. (4) This extra head of the biceps joined the bicipital aponeurosis from below as a flattened aponeurotic expansion. The ulnar nerve was situated behind the medial inter-muscular septum. No anomaly in the triceps muscle was observed. The superficial flexor group of muscles of the forearm presented an unusual proximal extension of origin that appeared to extend upwards up to the lower parts of the medial inter-muscular septa and the tunnel. The median nerve and the brachial artery passed inside the tunnel with the former being medial to the later. No branching could be detected in either of the structures inside the tunnels after they were opened by dissection on both the sides.

\section{DISCUSSION}

Entrapment neuropathies of the peripheral nerves are not uncommon occurrences in clinical practice. The median nerve can get entrapped at several distinct anatomical sites from the upper arm up to the carpal tunnel as comprehensively documented by Birch et al. and Bilecenoglu et al. The nerve becomes compressed and remains tethered to the structures forming the tunnel and loses its mobility. Any movement in a nearby joint stretches the nerve. Longstanding entrapments of the median nerve characteristically result in neuropathies, muscle weakness and wasting (Birch et al.; Green et al., 1999). On account of close proximity of the brachial artery to the median nerve, entrapment of the median nerve usually accompanies concomitant compression of the brachial artery. Compression of the artery is aggravated by spasm in the additional fibres of the muscles or by their hypertrophy. A compromise in vascularity of the forelimb by compression of the brachial artery produces claudicating pain in the upper limb. The case presented in this study is quite rare to come across as it exhibits: (1) bilateral occurrence of the musculo - aponeurotic tunnel, since bilateral arm and forearm muscle variations have been reported very rarely (Nakatani et al.,1998) specially with such long tunnels that trap the neurovasculature, (2) unusually long tunnels for the neurovascular bundles, (3) additional origins of the biceps brachii muscle in both the arms, (4) additional fibres of origin descending from the lower part of the left tunnel and the medial intermuscular septa, crossing across the elbow towards the superficial group of forearm flexors (suggesting higher origin of the common flexors in the arm). Additional origins of forearm muscles may be explained as evolutionary remnants as suggested by Wood (1867). It is therefore important to be aware of entrapment situations occuring bilaterally in an individual as reported here with additional origins of muscles in the vicinity of the neuro-vascular structures. Vascular and nerve entrapment symptoms can easily be treated with the release of these entities from the offending structures. Prior knowledge of such possibilities is helpful for the clinician to suspect such a diagnosis even in the face of conflicting diagnostic tests that are used to detect such situations.

MAHATO, N. K. Compresión bilateral del nervio mediano y la arteria braquial en la parte distal del brazo: reporte con origen adicional bilateral del músculo bíceps braquial. Int. J. Morphol., 28(4):1241-1244, 2010.

RESUMEN: No es infrecuente observar atrapamientos neuro-vasculares asociados con variaciones en el origen de los músculos del brazo. A pesar de haberse observado cabezas adicionales del músculo bíceps braquial y fibras extra del músculo braquial raramente estas cabezas adicionales bilaterales han sido causantes de la compresión del nervio mediano y de la arteria braquial. En este trabajo presentamos las cabezas del músculo bíceps braquial originándose en gran parte en el tabique intermuscular medial compartiendo su origen con el músculo braquial. Los orígenes adicionales del músculo forman largos túneles músculo fasciales. Los túneles miden $8 \mathrm{~cm}$ de longitud, y se extienden desde la parte inferior del brazo hasta la fosa cubital. Tanto el nervio mediano como la arteria braquial pasan por el túnel. La parte inferior del túnel izquierdo dio origen a fibras pertenecientes al músculo flexor superficial del antebrazo. Las estructuras neurovasculares no otorgaron colaterales en el túnel. El conocimiento de estas variaciones puede ayudar a los clínicos en el diagnóstico y el tratamiento de neuropatías y compromiso vascular

PALABRAS CLAVE: Nervio mediano; Arteria braquial ; Músculo bíceps braquial; Neuropatía por compresión; Tabique intermuscular. 


\section{REFERENCES}

Bassett, F. H.; Spinner, R. J. \& Schroeter, T. A. Brachial artery compression by the lacertus fibrosus. Clin. Orthop. Relat. Res., 307:110-6, 1994.

Bilecenoglu, B.; Uz, A. \& Karalezli, N. Possible anatomic structures causing entrapment neuropathies of the median nerve: An anatomic study. Acta Orthop. Belg., 71:169-76, 2005.

Birch, R.; Bonney, G. W. \& Wynn Parry, C. B. Surgical Disorders of the Peripheral Nerves. London, Churchill Livingstone, 1998. pp.282-5.

Gessini, L; Jandolo, B. \& Pietrangeli, A. Entrapment neuropathies of the median nerve at and above the elbow. Surg. Neurol., 19:112-6, 1983.

Green, D. P.; Hotchkiss, R. N. \& Pederson, W. C. Green's Operative Hand Surgery. $4^{\text {th }}$ ed. Philadelphia, Churchill Livingstone, 1999. pp.1417-22.

Loukas, M.; Louis, R. G. Jr.; South, G; Alsheik, E. \& Christopherson, C. A case of an accessory brachialis muscle. Clin. Anat., 19(6):550-3, 2006.

McNamara, B. Clinical anatomy of the median nerve. ACNR., 2(6):19-20, 2003.

Nakatani, T.; Tanaka, S. \& Mizukami, S. Bilateral fourheaded biceps brachii muscles: the median nerve and brachial artery passing through a tunnel formed by a muscle slip from the accessory head. Clin. Anat., 11(3):209-12, 1998.

Rodríguez-Niedenführ, M.; Vázquez, T.; Choi, D.; Parkin, I \& Sañudo, J. R. Supernumerary humeral heads of the biceps brachii muscle revisited. Clin. Anat., 16:197-203, 2003.

Williams, P. L.; Warwick, R.; Dyson, M. \& Bannister, L. H. Muscles of the upper arm. In: Gray's Anatomy. $37^{\text {th }} \mathrm{ed}$. New York, Churchill Livingstone, 1989. pp.614-6.

Wood, J. On human muscular variations in relation to comparative anatomy. J. Anat. Physiol., 1:44-59, 1867.

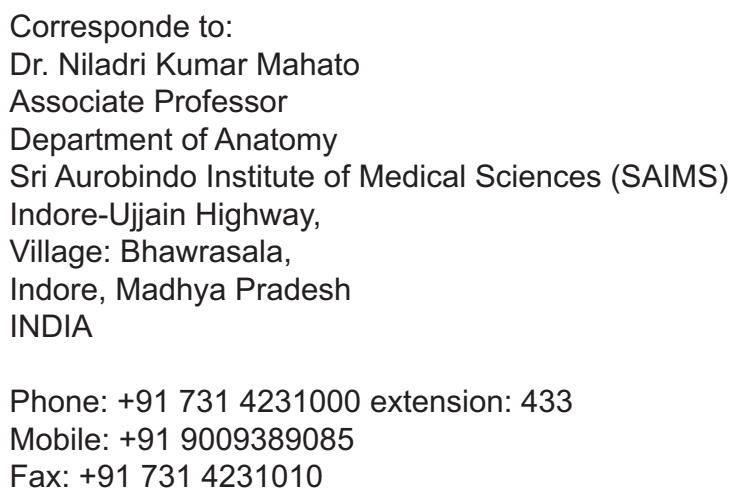

Email address: mahatonk@yahoo.co.in

Received: 27-11-2009

Accepted: 13-08-2010 